\title{
Arcus senilis: its relation to certain attributes and risk factors in patients with coronary heart disease
}

\author{
Noel Hickey, Brian Maurer ${ }^{1}$, and Risteárd Mulcahy \\ With the statistical assistance of J. W. NcGilvray \\ From the Coronary Heart Disease Research Unit, St. Vincent's Hospital, and the \\ Departments of Medicine and Social Medicine, University College, Dublin 2, Republic of Ireland
}

The frequency and degree of arcus in relation to a number of attributes or risk factors were tested in 534 male patients of all ages with coronary heart disease.

Frequency and degree of arcus were positively associated with age and with lifetime alcohol intake. Arcus was negatively associated with obesity. All other correlations proved negative.

The link between precocious arcus senilis and coronary heart disease is discussed. This investigation failed to show any relation between the acknowledged high-grade coronary heart disease risk factors and arcus senilis. It is suggested that the relation between arcus and alcohol intake merits further investigation.

The term arcus senilis implies that arcus is a manifestation of old age. The fact that it is not confined to older people confirms that there are accelerating factors operating in its causation. There are some reports that arcus is more likely to occur in patients with coronary heart disease than in healthy controls (Pomerantz, 1962; Shanoff and Little, 1964; Rifkind, I965). It is pertinent then to attempt to relate arcus with other factors which may be associated with or predictive of coronary heart disease. While arcus occurs commonly, though not invariably, in familial hypercholesterolaemia and xanthomatosis, it has not been adequately correlated with other atherogenic or risk factors.

This paper records the incidence and degree of arcus in patients with coronary heart disease. It examines the possibility of an association between arcus and a number of the patients' attributes, some of which are considered to be associated with or causative of coronary heart disease.

\section{Subjects and methods}

Five hundred and thirty-four male patients of all ages with coronary heart disease were examined routinely for the presence of arcus. Of these, 474

Received 17 October 1969.

1 Present address: Hammersmith Hospital, London WI2. were in the age-groups 35-69. All patients were admitted to hospital for a detailed case history, and all had proven acute coronary insufficiency or myocardial infarction as manifested by typical pain and by electrocardiographic abnormalities and, in the case of myocardial infarction, by serial enzyme changes. Detailed diagnostic criteria have been previously defined by us (Mulcahy and Hickey, 1966).

For the purpose of this communication the following factors were studied in relation to arcus: age, life-long cigarette smoking, diastolic blood pressure, alcohol intake, obesity, fat folds, glucose tolerance, total lipids, and serum cholesterol.

Arcus was classified into five grades: grade $I$, absent; grade 2, faint translucent segment; grade 3 , definite semitranslucent segment; grade 4, complete or incomplete opaque segment; grade 5, very heavy complete opaque arcus.

In interpreting the results, grades $\mathrm{I}$ and 2 were incorporated in the normal group, grade 3 was classified as moderate arcus, and grades 4 and 5 were classified as heavy arcus.

Cigarette smoking Cigarette smoking experience is recorded as a 'cigarette index'. This is a quantitative expression of lifetime smoking, and the index is derived from the product of the average daily consumption of cigarettes by the number of years smoking (Mulcahy and Hickey, 1966).

Diastolic blood pressure This was estimated as the mean of all readings on the fourth day of hospital bed-rest, before hypotensive treatment, when indicated, was started. 
Alcohol intake This was measured from the patient's lifetime drinking habits. If a significant change occurred in drinking habits 5 years or more before the collection of data the later drinking experience was recorded. The alcohol intake was measured by the following grading system: grade I, no alcohol; grade 2, casual or occasional drinking; grade 3 , constant but controlled drinking; grade 4, heavy uncontrolled drinking.

Obesity This was estimated as the percentage above or below ideal weight, as measured by age, height, and body frame, and was derived from tables of the Metropolitan Life Insurance Company (1959).

Fat folds These were measured with the standard Harpenden calipers, and in this study the right subscapular fat fold was used.

Total serum lipids These were measured by the turbidimetric methods of Kunkel and Ahrens (I948) and serum cholesterol was determined by Zak's colorimetric methods (I957).

Glucose tolerance This was expressed as the aggregate of fasting, half-hour, I-hour, and 2-hour readings. Blood sugar was estimated by the method of Folin and Wu (I920).

\section{Results}

In Table I degree of arcus is related to age for 474 patients between 35 and 69 years. There is a significant increase in the relative frequency and degree of arcus with increasing age $(\mathrm{p}<0.0 \mathrm{I})$.

Table 2 records, for each arcus group, the mean values for 6 variables examined in relation to arcus (age-group 35-69 years). For comparative purposes these data must be corrected for age. There is no apparent relation between degree of arcus and diastolic blood pressure, glucose tolerance, total serum lipids, and cigarette index, after standardizing for age in all cases.

We measured the current smoking habits in 390 of these 474 patients. No significant differences in volume of current smoking were found in the different arcus groups, nor were there differences in the degree of arcus in smokers, ex-smokers, or non-smokers.

Table 2 shows that obesity is significantly lower in patients with heavy arcus $(4+5)$ compared with patients with 'negative' arcus $(I+2) \quad(p<0.01)$. Obesity appears to be negatively associated with degree of arcus. Similarly, fat folds decline in the heavy arcus group but not significantly so.

In Table 3, the relation between degree of arcus and serum cholesterol is examined by age-group. There is no significant association between serum cholesterol and degree of arcus within age-groups or for all age-groups taken together. Table 3 does show, however, that
TABLE I Incidence of arcus in 474 patients in 5-year age-groups under 70 years

\begin{tabular}{lllll}
\hline $\begin{array}{l}\text { Age } \\
\text { (yr.) }\end{array}$ & $\begin{array}{l}\text { Arcus } \\
\text { absent }\end{array}$ & $\begin{array}{l}\text { Moderate } \\
\text { arcus }\end{array}$ & $\begin{array}{l}\text { Heavy } \\
\text { arcus }\end{array}$ & \\
\cline { 2 - 5 } & $\begin{array}{l}\text { Grades } \\
\text { I+2 }\end{array}$ & $\begin{array}{l}\text { Grades } \\
\text { Grades }\end{array}$ & $\begin{array}{l}\text { Gradal } \\
4+5\end{array}$ \\
\hline $35-39$ & 13 & - & - & 13 \\
$40-44$ & 34 & 4 & 2 & 40 \\
$45-49$ & 56 & 8 & 4 & 68 \\
$50-54$ & 55 & 13 & 14 & 82 \\
$55-59$ & 62 & 29 & 17 & 108 \\
$60-64$ & 56 & 21 & 15 & 92 \\
$65-69$ & 35 & 24 & 12 & 71 \\
\hline Total & 311 & 99 & 64 & 474 \\
\hline
\end{tabular}

$\chi^{2}=36.5 ;$ d.f. $=$ ro; $p<0.01$.

TABLE 2 Relation between arcus senilis and certain attributes or risk factors in 474 patients between 35 and 69 years

\begin{tabular}{|c|c|c|c|c|}
\hline \multirow[t]{2}{*}{ Variable } & \multirow[t]{2}{*}{ No. of cases } & \multicolumn{3}{|c|}{ Mean values for arcus grades } \\
\hline & & $I+2$ & 3 & $4+5$ \\
\hline $\begin{array}{l}\text { Diastolic blood pressure } \\
\text { Glucose tolerance } \\
\text { Total serum lipids } \\
\text { Cigarette index } \\
\text { Obesity } \\
\text { Fat folds }\end{array}$ & $\begin{array}{l}471 \\
436 \\
342 \\
473 \\
468 \\
438\end{array}$ & $\begin{array}{r}82 \cdot 6 \\
538 \cdot 3 \\
614 \cdot 8 \\
669 \cdot 0 \\
111 \cdot 3 \\
14 \cdot 0\end{array}$ & $\begin{array}{r}83 \cdot 2 \\
528 \cdot 5 \\
596 \cdot 9 \\
715 \cdot 3 \\
109 \cdot 0 \\
14 \cdot 1\end{array}$ & $\begin{array}{r}85 \cdot 0 \\
551 \cdot 1 \\
619 \cdot 1 \\
794 \cdot 8 \\
106 \cdot 8 \\
12 \cdot 7\end{array}$ \\
\hline
\end{tabular}

older patients tend to have lower cholesterol levels in the heavy arcus group.

Table 4 shows the relation between alcohol intake and degree of arcus in 534 patients of all ages. For the purpose of this paper arcus grades 3,4 , and 5 have been taken together. There is a significantly positive association between alcohol consumption and degree of arcus $(p<0.01)$.

Correlation of alcohol experience with age in these 534 patients shows a significant negative association $(p<0.05)$. Age cannot, there-

TABLE 3 Relation between arcus and serum cholesterol in 425 patients, divided into different age-groups

\begin{tabular}{lllll} 
Age-group & No. of cases & \multicolumn{4}{l}{$\begin{array}{l}\text { Mean and standard deviation of serum } \\
\text { cholesterol for arcus grades }\end{array}$} \\
\cline { 3 - 5 } & & $I+2$ & 3 & $4+5$ \\
\hline $35-49$ & 109 & $226 \cdot 0( \pm 47 \cdot 1)$ & $269 \cdot 1( \pm 49 \cdot 8)$ & $278 \cdot 0( \pm 45 \cdot 85)$ \\
$50-59$ & 176 & $267 \cdot 8( \pm 53 \cdot 8)$ & $265 \cdot 4( \pm 52 \cdot 5)$ & $268 \cdot 8( \pm 50 \cdot 90)$ \\
$60-69$ & 140 & $257 \cdot 1( \pm 55 \cdot 4)$ & $257 \cdot 9( \pm 56 \cdot 3)$ & $250 \cdot 1( \pm 47 \cdot 40)$ \\
All ages & 425 & $264 \cdot 2( \pm 52 \cdot 2)$ & $262 \cdot 4( \pm 53 \cdot 6)$ & $265 \cdot 9( \pm 55 \cdot 50)$ \\
\hline
\end{tabular}


TABLE 4 Alcohol intake related to arcus grades in 534 patients of all ages

\begin{tabular}{lccl}
\hline \multirow{2}{*}{ Alcohol category } & \multicolumn{3}{l}{ Arcus category } \\
\cline { 2 - 4 } & $\begin{array}{l}\text { Grades } \\
I+2\end{array}$ & $\begin{array}{l}\text { Grades } \\
3-5\end{array}$ & $\begin{array}{l}\text { Total No. } \\
\text { of patients }\end{array}$ \\
\hline Group I & 81 & 35 & II6 \\
Group 2 & I8I & 82 & 263 \\
Groups 3+4 & 81 & 74 & 155 \\
\hline Total & 343 & I9I & 534 \\
\hline
\end{tabular}

$\chi^{2}=13.72 ;$ d.f. $=2 ; \mathrm{p}<0.01$.

See text for explanation of arcus and alcohol grading.

fore, be a common factor between arcus and alcohol. Indeed, this negative association between alcohol consumption and age strengthens the positive association between alcohol consumption and arcus noted by us.

There is no significant relation between alcohol consumption and serum cholesterol levels (Table 5).

TABLE 5 Alcohol intake related to serum cholesterol in 534 patients of all ages

\begin{tabular}{llll}
\hline $\begin{array}{l}\text { Alcohol } \\
\text { group }\end{array}$ & $\begin{array}{l}\text { No. of } \\
\text { cases }\end{array}$ & $\begin{array}{l}\text { Mean } \\
\text { cholesterol }\end{array}$ & $S D$ \\
\hline I & I16 & 259.6 & \pm 45.6 \\
2 & 263 & 263.6 & \pm 53.2 \\
3 & 139 & 268.4 & \pm 54.8 \\
4 & 16 & 252.8 & \pm 54.5 \\
\hline
\end{tabular}

Other data available to us from patients of all ages and both sexes with coronary heart disease and allied syndromes, including patients with 'silent' infarction and bundlebranch block, and including the 534 patients who are the subject of this report, show no relation between presence and degree of arcus and exercise experience (898 cases), haematocrit ( 868 cases), uric acid ( 750 cases), and serum magnesium (210 cases).

\section{Discussion}

In attempting to establish a possible relation between arcus and coronary heart disease, we have studied other patient attributes, including certain acknowledged risk factors. We confirm the reports of others (Rodstein and Zeman, 1963; McAndrew and Ogston, 1965) that arcus is age dependent. No significant relation or trend was noted when arcus was related to diastolic blood pressure, glucose tolerance, total lipids, cigarette smoking, and serum cholesterol. From other data available to us no correlation appears to exist be- tween arcus and exercise experience, haematocrit, uric acid, and serum magnesium.

Obesity shows a tendency to decrease with increasing degrees of arcus. This relation may result from a negative association between age and obesity, independent of arcus (Hollister, Overall, and Snow, 1967).

There was a significant positive association between alcohol intake and arcus $(p<0.01)$. No other common factor, such as age, could be found to account for this association. This relation between alcohol and arcus has not to our knowledge been reported before.

This study fails to identify any clear risk factors which might account for a possible association between arcus senilis and coronary heart disease. The results of prospective and case studies suggest that hypertension, cigarette smoking, diabetes mellitus, and hypercholesterolaemia are four major risk factors which may be causatively associated with coronary heart disease. In our experience none of these four factors correlated significantly with arcus, nor have we been able to find a positive correlation with overweight or total serum lipids.

The factor which most strongly correlated with arcus in our patients was alcohol intake. We have no reason to believe from our experience and from that of other workers in the prospective or case history studies that alcohol is causatively related to coronary heart disease. The relation between alcohol consumption and aortic atheroma was recently studied (Sackett and Winkelstein, 1967) but little if any correlation was noted. The relation between alcohol and arcus merits further study.

We are grateful to Dr. John Murphy and Dr. George Mullen for valuable assistance in this study and to Mr. Robert McFarlane for the lipid and cholesterol estimations.

We are grateful to Dr. Frank Anderson and his staff at the Computer Laboratory, University College, Dublin, for their advice and assistance.

\section{References}

Folin, O., and Wu, H. (I920). A system of blood analysis. Supplement I. A simplified and improved method for determination of sugar. Fournal of Biological Chemistry, 41, 367.

Hollister, L. E., Overall, J. E., and Snow, H. L. (1967). Relationship of obesity to serum triglyceride, cholesterol, and uric acid, and to plasmaglucose levels. American fournal of Clinical Nutrition, 20, 777 .

Kunkel, H. G., and Ahrens, E. H. (1948). Turbidimetric studies of serum lipids in liver disease. In Liver Injury: Transactions of the 7th Conference, $\mathrm{p}$. 93. Josiah Macy, Jr. Foundation, New York. 
McAndrew, G. M., and Ogston, D. (1965). Arcus senilis in middle-aged men. British Medical fournal, $1,425$.

Metropolitan Life Insurance Company, N.Y. (1959). Tables. Derived from Build and Blood Pressure Study, Society of Actuaries, 1959.

Mulcahy, R., and Hickey, N. (I966). Cigarette smoking habits of patients with coronary heart disease. British Heart fournal, 28, 404.

Pomerantz, H. Z. (1962). The relationship bettveen coronary heart disease and the presence of certain physical characteristics. Canadian Medical Association fournal, 86, 57.

Rifkind, B. M. (1965). The incidence of arcus senilis in ischaemic heart-disease: its relation to serumlipid levels. Lancet, r, 312.
Rodstein, M., and Zeman, F. D. (1963). Arcus senilis and arteriosclerosis in the aged. American fournal of the Medical Sciences, 245, 70.

Sackett, D. L., and Winkelstein, W. (1967). The relationship between cigarette usage and aortic atherosclerosis. American Fournal of Epidemiology, 86, 264.

Shanoff, H. M., and Little, J. A. (1964). Studies of male survivors of myocardial infarction due to "essential" atherosclerosis. III. Corneal arcus: Incidence and relation to serum lipids and lipoproteins. Canadian Medical Association fournal, 91, 835.

Zak, B. (1957). Simple rapid microtechnic for serum total cholesterol. American fournal of Clinical Pathology, 27, 583. 